\title{
CONFLITO E REGULAÇÃO DAS ÁGUAS NO BRASIL - a experiência do Salitre
}

\author{
Renata Alvarez Rossi* \\ Elisabete Santos**
}

\begin{abstract}
Neste texto, discute-se a dimensão política dos conflitos socioambientais que envolvem as águas no Brasil, no atual contexto da Lei das Águas (Lei Federal No 9.433/97), considerando, especificamente, como tais conflitos se configuram na bacia do Rio Salitre, localizada ao Norte do estado da Bahia, historicamente caracterizada pela escassez. A metodologia utilizada consistiu em análise bibliográfica, discussão de dados secundários e de pesquisa direta com sujeitos sociais e representantes de organizações que atuam na referida região. A principal conclusão do estudo é que, no Brasil, os conflitos em torno das águas geralmente são caracterizados a partir de uma perspectiva pretensamente técnica, pela relação entre demanda e oferta por água, bem de sua regulação, de caráter explicitamente político, ou seja, que remete a formas de apropriação e a relações de poder que privilegiam interesses dos grandes usuários, sendo a bacia do Salitre considerada como típica.

Palavras-chave: Águas. Conflito. Socioambiental. Regulação. Salitre.
\end{abstract}

\section{INTRODUÇÃO}

Neste trabalho, analisa-se a dimensão política dos conflitos socioambientais que envolvem as águas no Brasil, no atual contexto da Lei das Águas (Lei Federal $n^{\circ}$ 9.433/97), e, especificamente, como tais conflitos se configuram na bacia do Rio Salitre, localizada ao norte do estado da Bahia, historicamente caracterizada pela escassez. Essa abordagem se justifica pela necessidade de aprofundar o conhecimento sobre conflito e regulação das águas num país que possui a maior reserva de água doce do mundo e que também convive com situações de extrema escassez. Discute-se, aqui, a tese de que os conflitos em torno das águas no Brasil, geralmente caracterizados a partir de uma perspectiva pretensamente técnica, como resultado da relação entre demanda e oferta por água, bem como de como sua regu-

* Universidade Federal da Bahia. Escola de Administração. Centro Interdisciplinar de Desenvolvimento e Gestão Social - Ciags.

Av. Reitor Miguel Calmon s/n. Cep: 40.110-903. Vale do Canela-Salvador - Bahia - Brasil. renatarossi2011@gmail.com

* * Universidade Federal da Bahia. Escola de Administracão. Departamento de Finanças e Política Pública.

Av. Reitor Miguel Calmon s/n. Cep: 40.110-903. Vale do Canela - Salvador - Bahia - Brasil. betesantos@ufba.br lação, têm um caráter explicitamente político, ou seja, nos remetem a formas de apropriação e relações de poder que privilegiam interesses dos grandes usuários, sendo a bacia do Salitre considerada como típica. O modelo de regulação em curso, particularmente instituído por meio da Lei Federal n 9.433/97, apesar de avançar no processo de descentralização da gestão, pouco tem contribuído para o equacionamento dos referidos conflitos, sendo a Bacia do Salitre um exemplo de como a ação de organizações de trabalhadores rurais se contrapõe a interesses e práticas econômicas geradoras de conflito e produtoras de escassez.

Estruturam esse trabalho os conceitos de conflito socioambiental e regulação. Na reflexão empreendida, um dialogo é estabelecido com os trabalhos de autores como Alketa Peci, Francis Wolff, Henri Acserald, Esteban Castro e Andrea Zhouri. O método de pesquisa utilizado consistiu na análise de dados secundários de textos e relatórios técnicos e na realização de entrevistas semidirigidas com sujeitos sociais envolvidos, de forma direta ou indireta, em situações de conflito na Bacia do Rio Salitre. Com este trabalho, espera-se contribuir 
para a produção de conhecimento sobre aspectos estruturantes que conformam experiências particulares de gestão das águas, produzindo subsídios para a constituição de novos modelos de gestão e de novas possibilidades de exercício da cidadania, capazes de viabilizar o acesso democrático às águas, bem como a defesa e a recuperação desse bem finito e essencial à vida.

\section{CONFLITO SOCIOAMBIENTAL E REGULAÇÃO}

A literatura sobre o conceito de conflito é vasta, e muitas de suas vertentes guardam um forte vínculo com a tradição positivista, sobretudo com a percepção de que o conflito é um elemento anômico e disfuncional, a ser extirpado ou domado. Quando associado ao qualificativo "ambiental", esse sentido ganha maior expressão pelo fato de ter como referência, às vezes, uma noção romântica e idílica da natureza, concebida originalmente em estado de equilíbrio, situação rompida pela ação do homem. Muitas dessas abordagens partem do pressuposto de que a presença do conflito é resultante do descompasso entre demanda e oferta, da ausência de instituições voltadas ao disciplinamento dos conflitos ou do seu fun$\infty$ cionamento inadequado, da falta de liderança ou de formação técnica, ou mesmo do não recurso à técnica ou à ciência como elemento estruturante de gestão (Castro, 2010). Esse tipo de abordagem, em geral, vem acompanhado de recomendações relativas à reestruturação organizacional, à capacitação técnica e a processos de "negociação" (Acserald, 2004, p. 10). Tais \& percepções, muitas vezes, têm a pretensão de iे solucionar conflitos socioambientais através

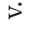
da identificação de formas mais adequadas de gestão da escassez, da qualificação técnica e da melhoria do desempenho organizacional, da crítica ao desperdício e ao consumismo, da administração mais eficaz ou eficiente das externalidades negativas das atividades econômicas, tornando "sustentável" as formas de apropriação dos elementos e bens ambientais.

Dentre as variadas abordagens situadas nesse campo teórico, destacam-se aquelas inspiradas na economia neoclássica, que tentam explicar a crise e os conflitos socioambientais a partir de uma genérica noção de escassez e da problematização da relação entre oferta e demanda de recursos naturais. Um marco importante nesse tipo de debate é a publicação, em 1972, do Relatório Meadows, ou Relatório do Clube de Roma, como ficou conhecido, que coloca a noção de escassez no centro do debate sobre as condições de produção e reprodução do capitalismo. O referido Relatório chama a atenção para os impactos ambientais resultantes do processo de acumulação e o potencial de conflito gerado pelo uso intensivo de recursos naturais. Assim, no contexto de crise dos anos setenta, colocou-se em questão a lógica de acumulação fordista, geradora de desequilíbrios ambientais, emergindo uma discussão sobre alternativas dentro do próprio sistema para o equacionamento dos limites ao crescimento econômico. Nesse caso especifico, o equacionamento dos conflitos socioambientais deveria se dar pela regulação da demanda, através da mudança nos padrões de consumo e da administração da oferta, com a identificação de novas fontes de recursos, condição necessária à ampliação dos limites de crescimento econômico de então. De uma maneira geral, as soluções para os conflitos socioambientais são atribuídas à gestão dos recursos, à tecnologia e às instituições do próprio sistema.

Essa forma de conceituação e de tentativa de equacionamento do conflito socioambiental despolitiza o debate teórico e resulta no que autores como Francis Wolff (2014) chamam de fetichização da ciência e da técnica, além da "cientificização" da gestão, por atribuir-lhes competências que elas efetivamente não têm. Assim circunscritos, tais argumentos e proposições se convertem em artifícios retóricos e retiram do debate sobre conflito socioambiental o caráter de classe das distintas formas de apropriação da natureza e do perma- 
nente conflito entre interesses, públicos, coletivos, difusos e privados, no atual contexto das sociedades produtoras de mercadorias. É exatamente nessa crítica que as noções de conflito e de política se encontram. A explicitação dessa relação tem como requisito teórico e prático a retomada da crítica das tentativas de cientificização da gestão e do debate sobre a natureza política dos conflitos socioambientais.

As análises dos incontáveis registros de conflitos socioambientais nas últimas décadas demonstram uma clivagem entre classes sociais nas distintas formas de apropriação dos recursos da natureza, sobretudo quando se coloca em questão a assimétrica relação entre valor de uso e valor de troca de elementos da natureza, convertidos em bens ambientais (Wolff, 2014). Várias são as tentativas de caracterização e equacionamento do conflito socioambiental que colocam a dimensão propriamente política no centro do debate. A título de exemplo, teóricos e militantes do movimento de justiça ambiental defendem a tese de não ser possível compreender os conflitos ambientais sem colocar, em primeiro plano, a natureza das relações sociais que estruturam a sociedade moderna. Isso significa que a relação entre homem e natureza se encontra mediada (alguns definem como subordinada) pelas relações sociais e de classes, consideradas como estruturantes e, consequentemente, como determinantes das situações de conflito ambiental (Acserald, 2004). Esses conflitos se materializam em embates que envolvem, por exemplo, interesses privados de corporações transnacionais e interesses públicos ou, melhor dizendo, interesses coletivos e difusos (Castro, 2009). Para essa vertente de análise, os incontáveis registros de conflito, nas últimas décadas, resultam, na verdade, das desiguais formas de uso e de acesso aos recursos naturais e dos efeitos provocados por uma economia fundada na obsolescência programada, no uso predatório da natureza e na acumulação (Zhouri; Laschefski, 2010).

Quando falamos de conflito socioambiental, portanto, estamos, por exemplo, nos referindo: ao comprometimento da qualidade das águas e do ar, resultante de atividades mineradoras e fabris; à destruição da vegetação, fruto de processos de urbanização predatórios e excludentes; ao esgotamento de recursos não renováveis; e à alteração radical de processos biológicos, em geral motivados pela lógica da acumulação. Nesse cenário, merecem destaque as relações de conflito entre o "moderno" e o "tradicional", entre as relações sociais voltadas para a produção, em larga escala, de mercadorias ou infraestrutura produtiva (geração de energia, sistema viário, exploração de minério e petróleo e irrigação para a produção de biocombustíveis) e aquelas voltadas para a manutenção de modos de vida e de produção baseados em relações familiares, que são autônomas em relação à dinâmica do grande empreendimento agrícola, na maioria das vezes voltadas para a produção de commodities, e de cooperativas - a exemplo das comunidades indígenas, quilombolas, ribeirinhas e de agricultores familiares (Laschefski, 2010; Pereira; Penido, 2010; Sevá Filho, 2010).

Desse modo, ao qualificar o conflito ambiental como resultante de formas particulares de apropriação dos recursos ambientais que envolvem o embate entre interesses privados, públicos e comuns, entre o "moderno" e o "tradicional”, estamos afirmando que os conflitos resultam "desta rede intrincada de processos socioecológicos e políticos que põem, inelutavelmente, a natureza no interior do campo dos conflitos sociais" (Acserald, 2004, p. 9) e colocam em questão as consequências da conversão da ciência em força produtiva. O que efetivamente está em jogo quando nos reportamos à noção de conflito socioambiental, portanto, é a possibilidade ou impossibilidade de compatibilizar economia e ambiente, interesses público, coletivo, difuso e privado, no atual contexto de produção e reprodução social.

A noção de conflito socioambiental a que nos reportamos neste trabalho diz respeito, particularmente, ao embate, aberto, direto ou velado, entre os distintos interesses que gi- 
ram em torno da apropriação das águas. Assim posto, esse conceito nos reporta às dimensões concretas e objetivas, como também às subjetivas referentes ao acesso às águas no atual contexto de crise e escassez e busca articular os aspectos naturais e sociais, colocando a dimensão política em primeiro plano. Em sendo assim, colocamos em questão também o modelo de regulação ambiental difundido por instituições nacionais e internacionais, como o Banco Mundial, a Organização das Nações Unidas (ONU) e o Fundo Monetário Internacional (FMI), amplamente adotado por muitos países, sobretudo aqueles situados na periferia do capitalismo. Tal modelo apela para a instituição de recursos técnicos e organizacionais, de instrumentos econômicos na gestão de conflitos, buscando esmaecer contradições estruturais no uso e na apropriação da natureza.

\section{CONFLITO E REGULAÇÃO - A LEI DAS ÁGUAS (LEI FEDERAL N ${ }^{\circ}$ 9.433/1997)}

A regulação dos conflitos socioambientais no Brasil tem como uma das suas principais referências a Lei das Águas, instituída nos anos noventa do século passado, no contexto de um amplo programa neoliberal de renovação de స paradigmas da gestão pública. A flexibilização do papel do Estado como regulador - tanto de questões relacionadas à dinâmica da economia (em particular, a regulação sobre a concorrência e seus efeitos para a sociedade), como daquelas relacionadas à oferta de serviços públicos e garantia de direitos - se materializou, do ponto de vista institucional, dentre outras formas, na constituição das agências reguladoras. O modelo de agência adotado no Brasil teve como fonte de inspiração a experiência norte-americana, sobretudo pela determinação de atribuir a essas instituições independência política em relação às decisões sobre temas estruturantes da economia, condição considerada como fundamental para a eficiente alocação dos recursos em um contexto de forte presença do Estado na regulação social, como ficou marcada a experiência do New Deal (Peci, 2007).

No entanto, no Brasil, a criação das agências reguladoras se diferencia da experiência norte-americana e de outros países, em primeiro lugar, por não ter havido um processo amplo de discussão sobre o modelo de regulação. Segundo Peci (2007), em nossa experiência, "o primeiro passo foi o encaminhamento das leis e, depois, a discussão sobre os conceitos básicos do modelo" (Peci, 2007, p. 80). Em segundo lugar, na experiência brasileira, o afastamento das agências da dinâmica política significou a ampliação do espaço do mercado em substituição à burocracia estatal, inclusive com a privatização da oferta de serviços públicos - com destaque para os serviços de saúde, educação, telecomunicações - e das indústrias de base, com vistas à promoção da chamada eficiência econômica, acompanhada de um amplo programa de flexibilização de direitos sociais, com destaque para a precarização do trabalho. Ainda, segundo Peci (2007), não existiu, no Brasil, uma política regulatória, mas um processo de criação de novas instituições, guiado pelo que a autora qualifica como mimetismo de formas institucionais, sobretudo pela ausência de construção de consensos políticos, envolvendo a sociedade, em torno do modelo.

O fato é que, no contexto da Reforma do Estado brasileiro, a autonomia, a independência e a flexibilidade dos órgãos reguladores aproximaram a gestão pública dos princípios da gestão privada, sem a ampliação de direitos e o exercício de controle sobre a economia, em um período de forte crise econômica, desemprego e tensão social. Assim, mesmo prevendo instrumentos participativos, como colegiados de tomada de decisões, as agências reguladoras não se constituíram em espaços efetivamente públicos e democráticos, mas, ao contrário, catalisaram o processo de enfraquecimento das atribuições do Estado como agente de regulação (o que só reforça o seu caráter de classe social). Além disso, a implantação de novas instituições, combinada com a ausência 
de uma política regulatória (de qualquer natureza) resultou em modelos de gestão anódinos, marcados pela indefinição entre instrumentos típicos da administração direta e instrumentos baseados nos princípios gerenciais. Talvez devêssemos tão somente ressaltar o caráter de classe da "regulação" que se instituiu. Essa talvez seja exatamente a regulação necessária à retomada do processo de acumulação em um momento histórico no qual a escassez das águas passa a se constituir, simultaneamente, em um fator limitante do desenvolvimento e também em uma oportunidade de negócio.

Nesse contexto, com o propósito de regular a implementação dos instrumentos de gestão previstos na Lei das Águas (Lei Federal no 9.433/1997), é constituída a Agência Nacional das Águas (ANA). Portanto, a ANA é a responsável pelo planejamento dos usos das águas, pelo monitoramento de sua disponibilidade, pela outorga do direito de uso e de regulamentar a cobrança pelo uso da água bruta, Instrumento Econômico (IEs) de gestão que substitui (ou, segundo algumas leituras, complementa) os instrumentos de Comando e Controle (C\&C), que passa a ser a marca mais característica do que qualificamos como flexibilização da regulação das águas. Também é atribuição da ANA o estímulo à constituição de Comitês de Bacias, espaços colegiados de decisão e gestão das águas, previstos no novo modelo de regulação.

Vários têm sido os desafios enfrentados pelo Estado e pela sociedade no processo de implementação da Lei das Águas, particularmente em relação a seus objetivos e fundamentos. Merece destaque o questionamento de teóricos e de movimentos sociais acerca de um dos fundamentos da referida lei, segundo o qual a água se constitui em um bem econômico. Essa mesma lei afirma ainda o princípio de que a água é um direito e que é preciso garantir o seu acesso a todos. Mas, afinal de contas, como compatibilizar a condição de bem público, de acesso universal, e a condição de bem econômico, uma vez que a lógica econômica nos reporta ao embate entre oferta e demanda e, principalmente, à subordinação do valor de uso ao valor de troca?

Do ponto de vista operacional, um dos principais desafios postos pelo novo paradigma instituído pela Lei das Águas é o estímulo a seu uso múltiplo. Entretanto, segundo o Relatório "Conjuntura dos Recursos Hídricos", em sua mais recente versão (2014), da vazão de água consumida no país $\left(836 \mathrm{~m}^{3} / \mathrm{segundo}\right)$, $72 \%$ destinam-se à irrigação. Os usos animal, abastecimento urbano, industrial e abastecimento rural aparecem com $11 \%, 9 \%, 7 \%$ e $1 \%$, respectivamente.

Além de ter os usos múltiplos como objetivo e os instrumentos econômicos como fundamento, a Lei das Águas traz inovações relativas ao modelo de governança, com destaque para a criação dos Comitês de Bacias Hidrográficas, concebidos como uma espécie de "parlamento das águas”, no qual participariam representantes dos governos, dos usuários (dos diversos setores econômicos) e sociedade civil na decisão sobre os usos, a cobrança pelo uso de água bruta, a definição de preços a serem cobrados, as ações para conservação, dentre outros temas de relevância para a bacia. No entanto, é farta a literatura que discute o significado da descentralização no contexto de flexibilização da gestão pública, questionando o significado da gestão local, ou de governo local, como espaço próximo dos cidadãos e, portanto, mais democrático. Refletindo sobre esse processo, Francisco de Oliveira (2001) ressalta que, embora a ideia de governo e de desenvolvimento local possa criar um "lócus interativo de cidadãos, recuperando a iniciativa e a autonomia na gestão do bem comum", ela também pode "inserir-se numa estratégia de descentralização que agrave as desigualdades", sem que, ademais, signifique a ampliação da democracia (Oliveira, 2001, p.18).

A experiência de gestão das águas não escapa a esse dilema, visto que, como considera Martins (2003), "a democracia formal, presente na estrutura dos comitês, não resiste às relações de poder estabelecidas nos territó- 
rios” (Martins, 2003, p. 37), de modo que, em diversas experiências, é possível observar, por um lado, inúmeras dificuldades - de ordem estrutural e política - para o exercício da manifestação de interesses divergentes por parte da sociedade civil e, por outro, a captura dos fóruns pelos interesses economicamente dominantes. Essa possibilidade de "captura" é visível em experiências como a da bacia do rio Paraíba do Sul, onde, segundo os estudos de Abers e Keck (2004), é marcante a incidência de grupos economicamente mais influentes, "pois se trata de uma das regiões mais dinâmicas e industrializadas do Brasil, onde os interesses econômicos são poderosos e organizados" (Abers; Keck, 2004, p. 60).

Vistos desse modo, os comitês de bacias se revelam como espaços funcionais onde conflitos precisam ser negociados e atenuados, além de serem legitimadas as decisões tomadas sobre os diversos interesses que se enfrentam em torno dos usos das águas, e não exatamente como um espaço coletivo de formulação e efetivamente de tomada de decisões. Aqui, portanto, descentralização, participação e democracia não convergem, necessariamente.

É nesse contexto que organismos multilaterais de financiamento, a exemplo do Banco Mundial e do Fundo Monetário Internacional, passam a recomendar e a condicionar emprésป timos a países periféricos à constituição de mecanismos de regulação de conflitos que, pelo สี่ seu caráter ideológico, não têm sido capazes de responder ao acirramento dos embates que en-

\section{ÁGUA, CONFLITO E ESTADO NO} BRASIL - A EXPERIÊNCIA DO RIO SALITRE

Discutiremos, nesta seção, dados relativos aos conflitos socioambientais e à regu- lação no Brasil, com especial ênfase na Bacia do Salitre, com o objetivo de aprofundar a discussão sobre a tese de que os conflitos em torno das águas e sua regulação têm um caráter predominantemente politico. A associação de dados secundários com a produção de dados primários, por meio da realização de entrevistas semiestruturadas, permitiu a articulação de elementos de caráter objetivo e subjetivo, além da apreensão de dimensões sociais e políticas sobre a regulação das águas, o que se reflete nos processos de participação na formulação e implementação da política das águas, bem como naqueles de construção das representações de interesses públicos e privados.

As entrevistas foram realizadas com representantes dos órgãos e instituições responsáveis pela formulação e implementação da política das águas (Agência Nacional de Águas, CODEVASF) e com representantes dos segmentos estudados (trabalhadores rurais sem terra, comunidades tradicionais e empresários do agronegócio), além de pesquisadores sobre o tema. Foram considerados interlocutores relevantes, em cada um desses segmentos, aqueles que estavam mais diretamente envolvidos com as questões suscitadas pelo trabalho e com os conceitos nele implicados, isto é, representantes que, na prática, discutem e se relacionam com os conflitos referentes à regulação das águas, bem como aqueles que participam de sua gestão.

A bacia hidrográfica do Rio Salitre está localizada ao norte do Estado da Bahia, em região de clima semiárido que integra o chamado Polígono das Secas no Nordeste brasileiro. A bacia possui 13.467,93 km2 de área de drenagem, isto é, de área para onde as águas das chuvas convergem, formando o rio principal e seus afluentes, com $640 \mathrm{~km}$ de perímetro, cujos limites integram parte de oito municípios - Jacobina, Juazeiro, Miguel Calmon, Morro do Chapéu, Ourolândia, Campo Formoso, Mirangaba e Umburanas - e, integralmente, o município Várzea Nova ${ }^{1}$ (Figura 1).

${ }^{1}$ Não há dados precisos que informem o percentual da 
Figura 1 - Localização da Bacia Hidrográfica do Salitre

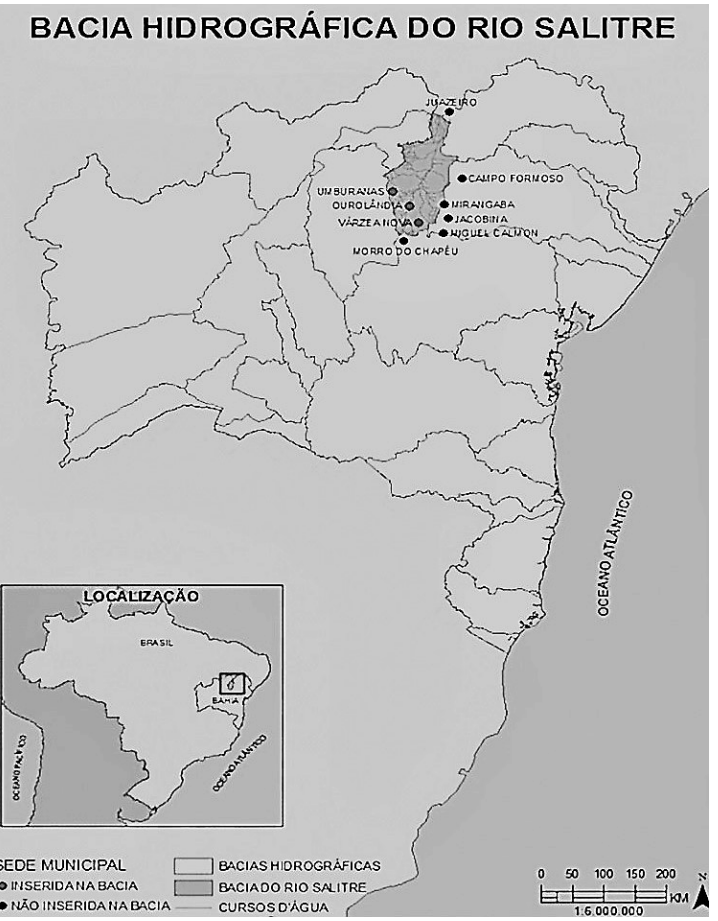

Fonte: Águas Brasil (2014)

O leito do principal rio da bacia, o Rio Salitre, possui $333,24 \mathrm{~km}$ de extensão, e está situado entre os municípios de Morro do Chapéu, onde está sua nascente, e Juazeiro, onde deságua no Rio São Francisco. Além do Salitre, compõem a bacia o Rio Vereda da Caatinga da Moura, o Rio Pacuí e o Rio Escurial. Lugar de pouca chuva, de média que varia de 400 a 800 $\mathrm{mm}$ por ano, concentrada nos meses de janeiro a abril, estima-se que, no total, 460 mil pessoas vivem nos municípios que integram a bacia, ${ }^{2}$

área de cada município dentro dos limites da bacia. Segundo o estudo realizado pelo GRH/UFBA (2002), aproximadamente $40 \%$ do município de Campo Formoso integra a bacia, e Mirangaba, Ourolândia e Várzea Nova possuem a sede dentro de seus limites. A ausência dessa informação impacta no recorte mais preciso de dados demográficos e de acesso aos serviços públicos. Como alternativa para este trabalho, optamos por traçar o perfil da bacia a partir dos dados do conjunto dos municípios, o que nos permite ter um panorama geral da região. Entretanto, é fundamental o aprofundamento de estudos que levem em consideração o recorte da bacia, tendo em vista a consolidação de sua condição de unidade de gestão, conforme define a Lei das Águas (Lei no. 9.433/1997).

${ }^{2}$ Nem todos os municípios integram totalmente a bacia Segundo informações do INEMA (2014), 96.951 habitantes vivem em seu limite. Em relação aos demais dados, optamos por traçar o perfil da região na qual a bacia se insere utilizando dados do conjunto dos municípios que a integram (total e parcialmente), devido à inexistência de dados relativos à bacia. preservando uma condição essencialmente rural, apesar do incremento da urbanização capitaneado pelo município de Juazeiro - cidade que comporta cerca de $40 \%$ dos habitantes da bacia. Em municípios como Campo Formoso, Ourolândia, Mirangaba e Umburanas, por exemplo, mais da metade da população se encontra na zona rural. ${ }^{3}$

A história da região do Rio Salitre é perpassada por conflitos que envolvem distintas formas de relação com a terra e com a água. Mais recentemente, a incorporação de modernas tecnologias de produção no cenário do semiárido tem aprofundado a exclusão de trabalhadores rurais, afastando-os das promessas do desenvolvimento econômico. O capital agrário, representado pelo agronegócio, como em nenhum outro tempo, ultrapassa fronteiras regionais e avança sobre o semiárido. Modernos instrumentos de gestão governamentais modificam - sem, necessariamente, transformar - o papel do Estado na regulação de relações sociais historicamente contraditórias e, por isso mesmo, conflituosas. O discurso oficial, tendo o Estado como promotor do desenvolvimento, enfoca a geração de emprego e renda para o camponês, uma narrativa aparentemente mais justa e inclusiva em tempos de democracia. Entretanto, o modelo implementado é o de produção de commodities, que se concretiza pela concentração de água e terra.

Nesse contexto, a ação do Movimento dos Trabalhadores Rurais Sem Terra (MST) no Salitre catalisa a formação do interesse público do trabalhador rural na região, isto é, a capacidade de organização coletiva voltada para a vida em comum, aqui representada pela unidade dos trabalhadores rurais em torno da água e da terra como meio de produção e reprodução da vida, em contraposição ao interesse privado, que tem, na água e na terra, os meios de acumulação de lucros. É na organi-

${ }^{3}$ São os seguintes os percentuais da população rural nos municípios da bacia: Campo Formoso, 62,7\%; Ourolândia, 61,4\%; Umburanas, 55,8\%; Mirangaba, 51,6; Morro do Chapéu, 42,4; Miguel Calmon, 39,3; Várzea Nova, 34,6; Jacobina, 29,5; e Juazeiro, 18,8 (IBGE, 2010). 
zação coletiva do MST que deságuam as esperanças do povo salitreiro, ao contestar a apropriação daquelas terras e daquelas águas com as quais possui uma relação de identidade, de pertencimento e de resistência à submissão ao trabalho assalariado.

A história do Salitre, portanto, é a historia da empreitada rumo ao desenvolvimento capitalista no campo, que não mede esforços para todo tipo de avanço, inclusive (sem nenhuma pretensão épica) sobre os modos de vida do "sertanejo", que diverge e resiste. Mas, afinal de contas, quem ganha e quem perde quando as terras e as águas do Salitre se tornam objeto de múltiplos interesses?

\section{A luta pela água no Brasil e no Salitre}

O "Mapa de Conflitos Envolvendo Injustiça Ambiental e Saúde no Brasil”, elaborado pela Fundação Oswaldo Cruz (Fiocruz; Fase, 2013), registra várias situações de comprometimento da qualidade das águas no país. ${ }^{4} \mathrm{O}$ Mapa descreve situações de conflitos que envolvem o assoreamento e a extinção de nascentes pelo desmatamento e ocupação das margens e do leito de rios, revelando a intensidade na utilização dos bens ambientais e a geração de da$\infty$ nos ao ambiente. O referido trabalho destaca : o significado social de tais danos ambientais, sobretudo pelo fato de que, em muitas situaฐู่ ções, os principais atingidos pelo comprometimento da qualidade das águas e pela escassez

$\dot{\not}$ tradicionais, entre as quais se destacam comuले nidades indígenas, quilombolas, ribeirinhas $\mathrm{e}$ $>$

gerazeiros. São comunidades que sofrem pela

${ }^{4}$ Além da CPT, outras iniciativas, no âmbito da academia స్ e de entidades sociais, têm buscado identificar e caracte- rizar situações de conflitos ambientais e pela água. Uma

I dessas experiências é o Mapa de Conflitos Envolvendo

Ơ Injustiça Ambiental e Saúde no Brasil (2013), elaborado

pela Fundação Oswaldo Cruz (Fiocruz) e pela Federação de

Orgãos para Assistência Social e Educacional (FASE), com

o apoio do Departamento de Saúde Ambiental e Saúde do

J Trabalhador do Ministério da Saúde (MS). desigualdade no acesso à terra, às águas e aos serviços públicos, como energia elétrica, habitação, saúde, educação, o que tem alimentado o histórico êxodo dos mais jovens e a exposição à exploração do trabalho em situações precárias, muitas vezes em condições análogas à da escravidão (Fiocruz; Fase, 2013).

Segundo as experiências catalogadas pelo referido Mapa, a mobilização dessas comunidades tem ocorrido através de ações diretas e de articulações com movimentos sociais, sindicatos, organizações nacionais e internacionais. Destaca-se, ainda, a violência praticada pelas empresas em relação às comunidades, com o uso da força privada, da coerção, de ameaças e desalojamentos. Em experiências relatadas no Mapa, é marcante a presença do Estado no financiamento de grandes empreendimentos, provocando deslocamentos e aprofundando os conflitos em torno do acesso às águas.

Em trabalho elaborado pela Comissão Pastoral da Terra (CPT) no ano de 2015, foram registrados, no Brasil, cerca de um conflito por água ou relacionado com as águas a cada três dias, envolvendo 42.337 famílias e 211.685 pessoas (CPT, 2002, 2015). ${ }^{5}$ Apesar da condição confortável em termos de quantidade de água no país, os principais elementos desencadeadores de conflito são a desigualdade no acesso, o comprometimento da qualidade ou a poluição de corpos d’água.

Conflitos relacionados à apropriação particular da água ocorrem por meio do barramento, de desvios de cursos d'água em propriedades de domínio privado, diminuindo ou impedindo o acesso em pontos ao longo dos rios (Malvezzi, 2015). Trata-se da construção de grandes obras hidráulicas de geração de energia e de captação de água para o uso por

\footnotetext{
5 São os seguintes os casos de conflito/número de famílias envolvidas no período de 2003 a 2015, registrados pela CPT: 2003: 20 casos/9.601 famílias; 2004: 60 casos/21.449 famílias; 2005: 71 casos/32.463 famílias; 2006: 45 casos/13.072 famílias; 2007: 87 casos/32.747 famílias; 2008:46 casos/27.156 famílias; 2009: 45 casos/40.335 famílias; 2010: 87 casos/39.442 famílias; 2011: 68 casos/27.571 famílias; 2012: 79 casos/31.874 famílias; 2013: 93 casos/26.967 famílias; 2014: 127 casos/42.815 famílias; 2015: 135 casos/42.337 famílias (CPT, 2015).
} 
empreendimentos privados, como ocorre nos perímetros de irrigação, muitos deles localizados em regiões semiáridas, como aquelas no entorno do Rio São Francisco. Ou ainda estão relacionados à atividade de mineração, a construção de barragens e açudes, a exemplo da implantação da Usina de Belo Monte no Pará e o rompimento da barragem de Fundão, de propriedade da empresa Mineradora Samarco, no município de Mariana em Minas Gerais. Nos últimos dez anos, o estado do Pará registrou o maior número de famílias (11.885) envolvidas em conflito, ou seja, $28,1 \%$, sobretudo em decorrência da Construção da Hidrelétrica de Belo Monte e da atividade de mineração. Em segundo lugar, está o Rio de Janeiro com 19,4\% (8.210 famílias), estando os conflitos relacionados à implantação do complexo industrial da Companhia Siderúrgica do Atlântico. Em terceiro lugar, o estado de Minas Gerais, que registrou o envolvimento de $16,3 \%$ das famílias (6.907), em decorrência de conflitos em torno da construção de barragens, açudes e da atividade de mineração. Em seguida aparecem os estados de Pernambuco, com 6.110 (14,4\%) e Bahia 2.687 (6,3\%), com conflitos relacionados ao uso das águas. Já no ano de 2015, os estados de Minas Gerais e Bahia registraram os maiores números de ocorrências: 54 e 27 casos, respectivamente, seguidos pelo Pará, com 15 ocorrências (CPT, 2015).

Figura 2 - Famílias envolvidas em conflito de água por estado da Federação

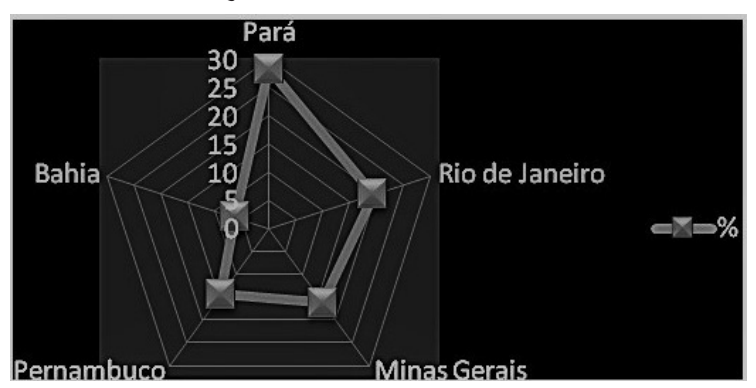

Fonte: Elaboração própria, dados da CPT (2015)

Na Bahia, os conflitos pelas águas envolvem comunidades remanescentes de quilombos, indígenas, comunidades de fundo e fecho de pasto, ribeirinhos, pescadores, posseiros, pequenos proprietários de terra e assentados de reforma agrária. Neste último caso, envolve movimentos de luta pela terra, como o Movimento dos Trabalhadores Rurais Sem Terra (MST) (CPT, 2014). Parte dos registros mais recentes de conflitos pela água ocorridos no estado tem relação com a prolongada estiagem, que teve início em 2012, quando 220 dos 417 municípios do estado decretaram situação de emergência (Bahia, 2014). Nessa situação foram registradas perdas totais de lavouras e animais, e o aumento da migração.

Na bacia do Rio São Francisco, em particular na bacia do rio Salitre, um de seus afluentes, os conflitos pelas águas ocorrem como resultado das históricas desigualdades no acesso, sendo acirrados com o incremento da atividade agrícola nos Perímetros de Irrigação implementados pelo governo federal através da Companhia de Desenvolvimento do Vale do São Francisco (CODEVASF), envolvendo empresas privadas do agronegócio, em especial os setores de frutas e de cana-de-açúcar. O uso intensivo das águas do Salitre para irrigação, exemplo raro de rio perene no semiárido, provocou sua completa exaustão, comprometendo as condições de permanência na terra das comunidades que tradicionalmente viviam em seu entorno.

Vários estudos têm identificado conflitos associados às desigualdades no acesso à água e à terra nessa região, sobretudo, em função do acesso privilegiado à água por empreendimentos privados que restringem o abastecimento da população, a qual que recorre ao abastecimento através de carros pipa, disponibilizados pelos poderes públicos municipais (Geografar, 2011). ${ }^{6}$ Essa situação tem levado à mobilização e à organização de comunidades atingidas pela escassez das águas. Como foi registrado no Mapa de Conflitos Ambientais (2013), "em ${ }^{6}$ Segundo trabalho realizado pelo Grupo de Pesquisa Geografar da UFBA (2011), muitos são os exemplos de conflitos em torno do barramento de água considerada, na maioria das vezes, como salobra e de péssima qualidade: Riacho Salitre, Alfavaca; Riacho Salitre; Riacho Salitre, Arame; Riacho Salitre, Campo dos Cavalos; Riacho Salitre, Curral Novo - Bananeira; Riacho Salitre, Horto; Riacho Salitre, Recanto; Riacho Salitre, Sabiá I; Riacho Salitre, Sabiá II. 
épocas de seca extrema, muitas famílias dessas comunidades têm recorrido à destruição da rede elétrica como forma de parar o bombeamento realizado rio acima e permitir que parte da água chegue às suas terras ou plantações, o que gera um contínuo clima de discórdia e violência na região" (Fiocruz; Fase, 2013).

O conflito entre trabalhadores rurais e os empreendimentos no Salitre, na Bahia, é um exemplo de que a modernização da economia, no Semiárido, pouco mudou as tradicionais formas de apropriação da água e da terra nessa região (o dono da terra é o dono da água), com efeitos sobre o aprofundamento da separação dos trabalhadores dos seus meios de vida, tornando-os permanentemente subordinados ao trabalho precarizado, como parceiros, meeiros e, finalmente, como operários da terra.

Segundo relato de um salitreiro:

Eu convivi muito com o pessoal mais velho. Naquele tempo, se trabalhava com a cana e se produzia rapadura. Eles alegavam que era um tempo bom. Ao mesmo tempo, diziam que era um tempo atrasado, que só compravam uma roupa, um calçado, de ano em ano, para ir para uma festa. [...] Uma parte deles tinha o que comer. Tinham rapadura para comer e vender, coco seco para levar para Juazeiro para trazer alimentos para os filhos. Passavam três dias e eles chegavam com arroz, feijão, farinha para dar de comer para os que ficaram [...]. Eles tinham a cana na beira do rio, tinham garapa da cana, rapadura, plantavam cebola, abóbora, irrigavam com uma cuia que se chamava passadeira. Ficavam espanando água. Plantavam batata na vazão, na umidade do rio e achavam que era tempo de fartura” (P. S. Entrevista, Salitre, dez. 2014).

Tais relações têm sido modificadas com a inserção do camponês, do trabalhador do Salitre na economia de mercado que avança sobre a região. O depoimento de um salitreiro que trabalhava nessas condições relata as diferentes formas de inserção produtiva em função da dificuldade de acesso à água e à terra:

A gente trabalhava sempre de empregado para os outros, de empregado diarista para os japoneses. O primeiro pessoal que botou irrigação aqui no Vale do Salitre foram os japoneses, que moram aqui na
Fazenda Arizona. A gente estava por aí na beira do rio perambulando e viemos para cá, para o Salitre. Terra boa... A gente veio para cá e começou a trabalhar como empregado para eles. No Salitre, começou a faltar água e eu comecei a trabalhar de meeiro, fui trabalhar em Sento Sé [...]. Fomos trabalhar de meeiro lá e eu ganhei um dinheirinho, comprei um pedacinho de terra do patrão e fiquei trabalhando. Trabalhamos uns três anos e depois eu retornei para cá. Vim de lá e comprei pedacinho de terra aqui. Aí vieram aquelas questões bancárias. Fiz o financiamento para investir na plantação, para ter manga, para ter maracujá, para ter pinha, para ter atemoia e para ter goiaba. Morreu tudo de sede. Até a algaroba morreu de sede lá. A seca entrou. Três anos de seca, liquidou tudo" (A. L. Entrevista, Juazeiro, dez. 2014).

As diferenças nas relações de trabalho entre pequenos proprietários minifundistas, parceiros, meeiros e diaristas são marcadas, fundamentalmente, pela relação com a terra e, por extensão, com a água. As relações de produção tradicionais foram sendo suplantadas no Salitre com o avanço das relações de mercado, em particular com o avanço da monocultura de cana-de-açúcar e da fruticultura irrigada, sendo o aumento da demanda de água por esses setores da economia o principal fator que inviabiliza a permanência do trabalhador rural na terra. Esse conflito fica claro em depoimento dos salitreiros:

Em minha fazenda [...] plantei, com sacrifício, 12 hectares de manga, dois de limão, sem custo de banco. Depois eu resolvi fazer um empréstimo no banco e colocar gotejo para economizar e, no fim, fiquei endividado. Até hoje estou endividado porque morreu tudo por falta de água” (P.S. Entrevista, Salitre, dez./2014).

\section{Em outro depoimento:}

A gente plantava para sobrevivência mesmo. Pouca coisa porque a gente não tinha condição de avançar muito [...]. A realidade começou a mudar quando começou a faltar água. Os grandes produtores usavam a água para irrigar e tiravam a água da gente sobreviver. A gente plantava para a sobrevivência e os grandes tiravam [...] A gente tinha uma areazinha de banana para sobrevivência e morreu de sede porque não teve mais água, o vizinho tirava toda. Foi desse jeito. A situação foi séria” (M. G. Entrevista, Salitre, dez. 2014). 
Sem água e sem-terra, ou seja, sem condições de manter-se no campo, a migração para as cidades ou o trabalho nas grandes plantações passam a ser a alternativa de sobrevivência do salitreiro. Em suma, os conflitos pelas águas envolvem disputas entre diversos usos e expressam a desigual correlação de forças entre proprietários de terras e de empreendimentos privados, como aqueles dos ramos do agronegócio, da indústria, da mineração e das hidroelétricas e, por outro lado, comunidades tradicionais, como indígenas, ribeirinhos, além de pescadores e trabalhadores rurais. A identificação dos sujeitos, da disputa entre os diversos usos, revela a dimensão política dos conflitos, ressaltando o embate entre distintos interesses que envolvem, por um lado, a necessidade do acesso às águas para a sobrevivência e manutenção de modos de vida e, por outro, o interesse pela água como insumo produtivo, que se apropria de bens comuns para a produção de riqueza apropriada de forma privada.

\section{ADMINISTRANDO CONFLITOS}

Os dados que registram o aumento de conflitos socioambientais no Brasil, exemplificado com a experiência do Salitre, atestam a natureza política da regulação das águas no país. Como foi anteriormente destacado, a implantação do referido Perímetro de Irrigação gerou expectativas na população local em relação à possibilidade de desenvolvimento regional. Embora o discurso oficial enfatizasse a possibilidade de participação de trabalhadores rurais vinculados à agricultura familiar, o que ocorreu, na prática, foi a destinação dos lotes irrigados para grandes e médios produtores, em geral, aqueles com capacidade de investimento, conforme declaração de representante da CODEVASF: “... se o agricultor não tiver tino empresarial, não adianta incluí-lo no Perímetro" (G. C. Entrevista. Juazeiro, 02/2014).

Nesse cenário, a CODEVASF teve um papel estruturante na produção e regulação dos conflitos socioambientais na referida bacia. Questionado sobre a possibilidade de incorporar a agricultura familiar no Projeto, o representante da CODEVASF afirma que o fundamental, na implementação do Perímetro Irrigado, é o atendimento aos critérios técnicos através da seleção das propostas com melhores perspectivas de produção e de produtividade (G. C. Entrevista. Juazeiro, 2014). A narrativa que persegue a produtividade exclui, na prática, os agricultores familiares e, particularmente, os salitreiros. O modelo de produção baseado na monocultura e no uso de agrotóxicos - incompatível com o modo de produção camponês - somado à dificuldade de acesso a crédito para investimentos selam a primazia do latifúndio e do agronegócio no Projeto Salitre.

Um morador da região, fazendo comentários sobre as promessas de integração no Perímetro, afirma: "Eu me iludi. Nós pensávamos que, quando se implantasse o Projeto Salitre, nós iríamos ter acesso à terra e à água, mas não tivemos. A concepção do Projeto Salitre foi para as grandes empresas" (D. V. Entrevista. Juazeiro, 2013). Por outro lado, consumada a implantação do Perímetro, a presença dos trabalhadores rurais - que, no caso do Salitre, organizaram uma ocupação de parte do terreno com cerca de 400 famílias mobilizadas com o apoio do MST - torna-se um incômodo, um empecilho ao desenvolvimento do Projeto. Segundo representante da CODEVASF, um dos principais problemas enfrentado no Perímetro Irrigado do Salitre "é a presença dos Sem Terra” (G. C. Entrevista. Salvador, 2014). O entrevistado é enfático ao afirmar que a presença do Movimento é um entrave ao seu pleno funcionamento, uma vez que "a ocupação de lotes pelo Movimento dos Sem Terra desestimula os empresários a investir no Perímetro" (G. C. Entrevista. Salvador, fev. 2014). O representante da Agroindústrias do Vale do São Francisco S/A (AGROVALE), com posição semelhante, afirma que, no local ocupado pelo MST, "poderíamos estar produzindo 125 mil toneladas de cana por ano. Se eu tenho um faturamento de 
$\mathrm{R} \$ 120,00$ por tonelada de cana, representa $\mathrm{R} \$$ 15.000.000,00 perdidos no faturamento da empresa por ano (G.H. Entrevista, Juazeiro, 2015). Ainda segundo o entrevistado, o impasse gera um ambiente de conflito: “... ninguém pode triscar, passar. A gente não passa nem perto. É uma guerra” (G. H. Entrevista, Juazeiro, jul. 2015).

Na ocupação do Perímetro Irrigado, os trabalhadores rurais organizados no MST retratam o papel que a agricultura camponesa ocupa no conjunto da produção do campo, com destaque para a produção de alimentos, em oposição à produção de commodities, como é o caso dos biocombustíveis. Segundo representante do MST, a ocupação do Projeto Salitre tem um significado politico:

Quando a gente ocupa o Perímetro, a gente está fazendo o enfrentamento com o agronegócio, com o capital. E estamos no semiárido, onde já tem uma questão forte da luta pela água. Tem aqui organizações que lutam pela água, mas o Movimento se diferencia porque, para nós, a água corre por cima da terra. Então, nós temos que lutar pela terra e pela água e entrar na terra onde já tem água. Onde tem terra e água e não tem gente? Nos perímetros irrigados. Se você for lá onde a AGROVALE planta quase 5.000 hectares de cana, não tem "um pé de gente". Tem só dois pistoleiros tomando conta e as canas... Água, terra e gente. Foi isso que o MST descobriu: que é possível fazer esse enfrentamento. É o lugar exato para fazer o enfrentamento, porque o conflito é real. Não é projeto futuro. Lá já tem água, já tem a terra. Então, é real, por mais que não gostem que a gente esteja lá, vão dizer o quê? Que o que a gente produz não é produção? Quem mais vendeu no CEASA nestes últimos dois anos foram os sem-terra" (D. R. Entrevista, Juazeiro, jul. 2015).

Nesse cenário, o principal sujeito da regulação é a CODEVASF, associada e articulada com órgãos estaduais e federais. O Comitê da Bacia Hidrográfica do Rio Salitre, criado em 2006, ocupa um lugar secundário, assim como é incidental a referência a órgãos envolvidos na regulação e na gestão das águas, ou a instrumentos de regulação previstos na Política Nacional das Águas na mediação ou equacionamento dos conflitos.
Por outro lado, segundo representante da Agência Nacional de Águas, a partir da deliberação de um processo de "negociação social" envolvendo os setores participantes do Comitê da Bacia do São Francisco, o setor agropecuário, maior usuário de água, se beneficia de "desconto de $97,5 \%$ em relação aos valores cobrados dos demais setores (aplicação do multiplicador Kt, ou seja, são 40 vezes menores que dos demais setores) e, assim, sua contribuição é de apenas 11\% do valor total cobrado" (Ana, 2013, p. 248). Como resultado, segundo o entrevistado, "tanto os agricultores com mais de 1.000 hectares irrigados (grandes propriedades) quanto os agricultores com menos de 5 hectares irrigados (pequenas propriedades) pagam menos de R\$ 10/hectare/ano pelo uso da água, independentemente da sua eficiência na utilização dos recursos hídricos e independentemente do valor agregado pela água à sua produção (G. B. Entrevista, Salvador, ago. 2015).

Nesse contexto, documentos oficiais elaborados pela ANA limitam a abordagem ao tema dos conflitos na Bacia do Rio Salitre como um fato decorrente de balanços desfavoráveis entre oferta e demanda por água, sem que sejam referidas as razões para esse desequilíbrio. Segundo a Resolução no 707/2004 da Agência Nacional de Águas, que trata dos procedimentos de natureza técnica e administrativa que orientam a análise de pedidos de outorga, o conflito de natureza quantitativa "será caracterizado pela relação entre demandas, estimadas por cadastros ou por dados secundários, relativas a consumos, captações ou vazões necessárias à manutenção de níveis d'água adequados ao uso e à disponibilidade hídrica” (ANA, 2014, p.5). Já o conflito de natureza qualitativa será caracterizado, segundo a mesma Resolução, "pela relação entre vazões necessárias à diluição de poluentes ou cargas de poluentes, estimadas por cadastros ou por dados secundários, e a disponibilidade hídrica” (ANA, 2014, p. 5). O controle do balanço hídrico, segundo a ANA (2013), por sua vez, deve "sistematizar o procedimento de balan- 
ço hídrico em um ambiente computacional de forma a calcular os indicadores nas situações menos críticas (em que o potencial de conflito é baixo) de forma automática, e, com isso, possibilitar que os especialistas antes alocados nesta tarefa pudessem focar em soluções para bacias mais críticas” (ANA, 2013, p. 44).

Em documentos como a "Conjuntura dos Recursos Hídricos no Brasil” (2009, 2011, 2013, 2014), referência oficial na discussão dos desafios da gestão das águas, os diversos usos das águas são mencionados como fonte potencial de conflitos sem que, no entanto, sejam qualificados os usuários, em termos políticos e econômicos, e seus interesses. Essa ausência torna-se ainda mais problemática quando a Política Nacional das Águas delega a arbitragem de situações de conflitos - além do Conselho Nacional de Recursos Hídricos (CNRH), instância máxima do Sistema Nacional de Gerenciamento de Recursos Hídricos (SINGREH) - aos Comitês de Bacias, cujas fragilidades, tanto de natureza institucional como política, podem inviabilizar uma efetiva atuação no sentido do equacionamento dos conflitos. Desse modo, as medidas adotadas em situações de conflitos, como a alocação negociada de águas - processo no qual os usuários decidem "com base nas previsões da disponibilidade hídrica nos meses subsequentes às chuvas, o quanto de água poderá ser utilizada por cada usuário ou setores usuários ao longo de determinado tempo" (ANA, 2013, p. 328) - e as campanhas de fiscalização visando a garantir a prioridade do abastecimento humano em situações de profundo estresse hídrico correm o risco de atuar tão somente nos efeitos e não exatamente nas causas dos embates.

Autores como Castro (2010), Zhouri (2010) e Laschefski (2005), além de Acserald (2004), têm feito uma reflexão crítica sobre o modo como os agentes da regulação ambiental têm tratado os conflitos relacionados com as águas no país, com a ênfase na situação de escassez. São justificadas as medidas que, ao final de contas, privilegiam grandes interesses eco- nômicos sem responder a questões de natureza essencialmente política. Esteban Castro (2010) menciona experiências de conflitos no México, onde a condição naturalmente árida de certas regiões nem sempre foi a causa para conflitos, enquanto que, regiões em condição confortável em termos de quantidade de água, eram enfrentados fortes embates pelo acesso e uso das águas (Castro, 2010). Por essa razão, para Castro:

\begin{abstract}
... explicar os conflitos pela água exige incorporar a dimensão social na análise e avançar no desenvolvimento de arranjos interdisciplinares que permitam identificar a interação entre os processos físico-naturais e sociais posto que não é possível dar por explicados estes conflitos, remetendo-se meramente a fatores como a escassa disponibilidade de água, aridez, ou a pressão do crescimento urbano (Castro, 2010, p. 192).
\end{abstract}

Acserald (2014) argumenta que o tratamento do tema dos conflitos pela via dos processos econômicos e a diluição de sua dimensão política também se configura como meio para tornar os territórios nacionais e subnacionais atrativos para investimentos de grandes empreendimentos privados. Nesse contexto é que se enseja a reformulação da regulação ambiental e, particularmente, do papel exercido pelos estados nacionais e pelas agências reguladoras na diluição (na verdade, transferência para a sociedade) dos impactos provocados pelas iniciativas de ampliação da acumulação, severamente afetada pelas recorrentes crises econômicas no contexto de globalização. Um dos mecanismos utilizados nesse processo de retomada da ampliação da acumulação é o que o autor chama de chantagem locacional dos investimentos, isto é, um "mecanismo através do qual os capitais móveis pressionam os poderes locais e os atores sociais menos móveis pela obtenção das condições sociais e ambientais as mais vantajosas para sua rentabilização" (Acserald, 2014, p. 94), sob pena de se transferirem para outro local que ofereça melhores condições em termos de legislação ambiental mais flexível, subsídios e financiamentos estatais e, sobretudo, mais "consentimento". 
A principal vantagem a ser oferecida por um país, estado ou município, ainda segundo o autor, é a menor probabilidade de existência de conflitos ou a existência de instituições capazes de contorná-los. É nesse sentido que, para Acserald e Bezerra

... ao mesmo tempo, ao escolherem o espaço mais rentável onde se relocalizar (ou seja, aqueles locais onde conseguem obter vantagens físicas e ambientais), acabam premiando com seus recursos os estados e municípios onde é menor o nível de organização da sociedade e mais débil o esforço em assegurar o respeito às conquistas legais. Ou seja, neste quadro político-institucional, os capitais conseguem, em níveis antes desconhecidos, internalizar a capacidade de desorganizar a sociedade, punindo com a falta de investimento os espaços mais organizados, e premiando, por outro lado, com seus recursos, os espaços menos organizados” (Acserald; Bezerra, 2009, p. 4-5).

É por essa razão que, para os autores, o que está na origem dos conflitos ambientais, na realidade, é o "choque entre o avanço da fronteira de exploração de recursos [propiciado pelo aumento da mobilidade do capital] com a disposição de sujeitos sociais localizados a dar outros sentidos a seus territórios" (Acserald; Bezerra, 2005, p. 34). Nesse contexto, a utilização de tecnologias de resolução de conflitos ambientais institucionaliza a despolitização dos dissensos e subordina, pela força de lei, os in$\infty$ teresses dos "mais fracos" aos dos "mais fortes". خิ É precisamente esse o significado que assume a flexibilização das leis ambientais que estabeleฮี่ ce (ex ante) as condições ideais para a expansão 仓 do capital sobre territórios e recursos naturais.

\section{CONCLUSÕES}

A investigação realizada ao longo deste trabalho reafirma a tese de que a caracterização e a regulação dos conflitos socioambientais em torno das águas no Brasil, a exemplo do que acontece na Bacia Hidrográfica do Rio Salitre, só podem ser compreendidos na sua inteireza e complexidade a partir da explicitação do caráter politico dos conflitos socioambientais. Isso signi- fica que os avanços na produção de conhecimento, na criação de instrumentos técnicos, importantes elementos no equacionamento da escassez, são acionados no contexto do embate entre os distintos interesses econômicos e conflitos gerados pelas relações de poder que permeiam as múltiplas formas de apropriação das águas.

De forma conclusiva, consideramos que, no Brasil, a regulação das águas tem se configurado como um exemplo de como demandas de cunho democratizante podem se associar a pressupostos e formulações tipicamente neoliberais e de como a regulação dos conflitos, nas instâncias participativas e deliberativas, ainda tem pouca eficácia na garantia dos interesses propriamente coletivos e difusos da natureza. Após duas décadas de sua instituição, a Lei das Águas vive uma situação de incompletude, e sua implementação oscila entre a resiliência da aplicação de instrumentos de comando e controle herdados do Estado burocrático e a implementação, incompleta, de Instrumentos Econômicos de gestão (IEs) típicos do modelo gerencial. Convive-se, assim, em um contexto político-institucional que, ao mesmo tempo em que desconstrói a estrutura regulatória tradicional, se mostra incapaz de realizar plenamente o princípio da universalização do direito à água e combater a escassez.

A regulação em curso no país, e no semiárido em particular, revela que, nas situações de conflito, as decisões sobre o uso das águas desafiam conhecimento e procedimentos técnicos estabelecidos e consolidados e, em muitas circunstâncias, obscurecerem relações de causalidade e legitimam intervenções e interesses hegemônicos. Em sendo assim, a gestão passa a se constituir na esteira de circunstâncias nas quais o aumento da degradação e, em particular, da escassez já se fazem presentes (em muitos casos, de maneira irreversível) no tradicional semiárido, como também em outros recantos do país - inclusive nos qualificados como desenvolvidos. Ironicamente, degradação e escassez têm impactado interesses econômicos os mais distintos, como a crise das 
águas em São Paulo e nas zonas de fronteira, no avanço de empreendimentos do agronegócio e onde a condição semiárida, associada ao elevado consumo de água para a irrigação, tem provocado fortes tensões envolvendo interesses públicos e privados.

Por outro lado, os conflitos que envolvem desigualdades no acesso às águas têm despertado a atenção da sociedade para a problemática das águas no Brasil, seja através de discursos mais genéricos associados ao direito dos consumidores (em particular nas áreas urbanas), seja como pauta de movimentos sociais já consolidados, movimentos ambientalistas, sindicais e de partidos políticos, ou mesmo como objeto de estudo na academia.

Em todos esses casos, deve-se notar que tais discussões extrapolam os espaços institucionais previstos no atual modelo de regulação, o que talvez seja explicado, por um lado, pela fragilidade dos mecanismos de participação da Política Nacional das Águas e, por outro, pela natureza e pelos limites dos princípios e instrumentos, tipicamente privados que orientam o atual modelo de regulação de conflitos. Assim, ao mesmo tempo em que as questões em torno das águas se complexificam, a regulação se revela, ou insuficiente, ou politicamente comprometida.

Nesse cenário, as divergências em torno dos princípios que consideram a água como um bem público e como um bem dotado de valor econômico acirram-se de tal modo, que o enfrentamento da tensão entre o público e o privado, no campo da regulação das águas, somente poderá ser equacionado no âmbito da luta política, e não pela via da deliberação meramente jurídica. Assim, conflitos pelas águas reacendem a discussão sobre a complexa relação entre sociedade e natureza, exigindo a compreensão do significado político da disputa entre interesses públicos e privados na apropriação das águas.

Recebido para publicação em 17 de novembro de 2016 Aceito em 27 de fevereiro de 2018

\section{REFERÊNCIAS}

ABERS, Rebecca; KECK, Margaret. Comitês de bacia no Brasil: uma abordagem política no estudo da participação social. Revista Brasileira de Estudos Urbanos e Regionais, Recife, v.6, n.1, maio 2004.

ACSERALD, Henri. As práticas espaciais e o campo dos conflitos ambientais. In: . Conflitos ambientais no Brasil. Rio de Janeiro: Relume Dumará/Fundação Heinrich Böll, 2004.

. Disputas cognitivas e exercício da capacidade crítica: o caso dos conflitos ambientais no Brasil. Revisto Sociologias, Porto Alegre, v. 16, n. 35, p. 84-105, jan./abr. 2014

ACSERALD, Henri; BEZERRA, Gustavo das Neves. Desregulação, deslocalização e conflito ambiental considerações sobre o controle das demandas sociais no Brasil contemporâneo. In: $13^{\circ} \mathrm{ENCONTRO}$ DA ASSOCIAĈ̃O NACIONAL DE PÓS-GRADUAÇ̃̃O E PESQUISA EM PLANEJAMENTO URBANO E REGIONAL. Florianópolis: ANPUR, 2009.

Inserção Econômica Internacional e "Resolução Negociada" de Conflitos Ambientais na América Latina. In: ZHOURI, Andréa; LASCHEFSKI, Klemens (Orgs.) Desenvolvimento e conflitos ambientais. Belo Horizonte: Editora UFMG, 2010.

AGUAS DO BRASIL. Bacia Hidrográfica do Rio Salitre: afluente do Rio São Francisco. Disponível em: http:// aguasdobrasil.org/edicao-06/bacia-hidrografica-do-riosalitre-afluente-do-rio-sao-francisco.html. Acesso em: jan. 2014

AGÊNCIA NACIONAL DE ÁGUAS (ANA). Conjuntura dos recursos hídricos no Brasil 2013. Brasilia: ANA, 2013.

. Conjuntura dos Recursos Hídricos no Brasil 2009. Brasília: ANA, 2014

BRASIL. Lei ${ }^{\circ}$ 9.433, de 8 de janeiro de 1997. Institui a política Nacional de recursos hídricos. Diário Oficial [da] República Federativa do Brasil, Poder Executivo, Brasília, DF, 09 jan. 1997.

COMISSÃO PASTORAL DA TERRA (CPT). Conflitos no campo. Goiânia: CPT Nacional - Brasil, 2002.

Conflitos no Campo. Goiânia: CPT Nacional Brasil, 2014

Conflitos no Campo. Goiânia: CPT Nacional Brasil, 2015.

CASTRO, Esteban. O estudo interdisciplinar dos conflitos pela água no meio urbano: uma contribuição da Sociologia. In: ZHOURI, Andréa; LASCHEFSKI, Klemens (Orgs.) Desenvolvimento e conflitos ambientais. Belo Horizonte: Editora UFMG, 2010.

Presentación. In:

$\overline{\text { Americanos. Sevilla, España, } 2009}$

Anuario de estudios

FIOCRUZ/FASE. Mapa de conflitos ambientais. Disponível em: www.conflitosambientais.org.br. Acesso em: fev. 2013.

INSTITUTO DO MEIO AMBIENTE E RECURSOS HÍDRICOS (INEMA). CBH Salitre. Disponível em: http:// www.inema.ba.gov.br/gestao-2/comites-de-bacias/comites/ cbh-salitre/. Acesso em: jan. 2014

MALVEZZI, Roberto. Conflitos por água nos últimos 10 anos. In: Comissão Pastoral da Terra (CPT). Conflitos no campo - Brasil 2014. Goiânia: CPT Nacional - Brasil, 2015. MARTINS, Rodrigo Constante. A Instrumentalização de políticas ambientais nas áreas rurais paulistas. In:

Uso e gestão dos recursos hídricos no Brasil: desafios teóricos e político-institucionais. São Carlos: RiMa, 2003.

OLIVEIRA, Francisco de. Aproximações ao enigma: que 
quer dizer desenvolvimento local? São Paulo: Instituto Pólis/EAESP/FGV, 2001.

PECI, Alketa. Regulação no Brasil: desenho, governança, avaliação. São Paulo: Editora Atlas, 2007.

PEREIRA, Doralice Barros; PENIDO, Marina de Oliveira. Conflitos em empreendimentos hidrelétricos: possibilidades e impossibilidades de (des)envolvimento social. In: ZHOURI, Andréa; LASCHEFSKI, Klemens (Orgs.)Desenvolvimento e conflitos ambientais. Belo Horizonte: Editora UFMG, 2010.

SEVÁ FILHO, Arsênio Osvaldo. Problemas intrínsecos e graves da expansão mineral, metalúrgica, petrolífera e hidrelétrica nas Amazônias. In: ZHOURI, Andréa; LASCHEFSKI, Klemens (Orgs.) Desenvolvimento e conflitos ambientais. Belo Horizonte: Editora UFMG, 2010.
SILVA, Demetrius David; PRUSKI, Fernando Falco. Gestão dos recursos hídricos: aspectos legais, econômicos, administrativos e sociais. Brasília/DF: Secretaria de Recursos Hídricos; Viçosa/MG: Universidade Federal de Vicosa; Porto Alegre: Associação Brasileira de Recursos Hídricos, 2000.

WOLFF, Francis. Apolitismo, a maior ameaça à democracia. Disponível em: < https://www.youtube.com/ watch?v=djTiMR6mAzU>. Acesso em: 24 de fev. 2014.

ZHOURI, Andréa; LASCHEFSKI, Klemens. Desenvolvimento e conflitos ambientais: um novo campo de investigação. In: . (Orgs.) Desenvolvimento e conflitos ambientais. Belo Horizonte: Editora UFMG, 2010. 


\section{CONFLICT AND REGULATION OF WATER IN BRAZIL - THE SALITRE CASE}

\author{
Renata Alvarez Rossi \\ Elisabete Santos
}

This paper discusses the political dimension of socio-environmental conflicts involving waters in Brazil, under the context of the current Lei das Águas (Federal Law No. 9.433/97), considering, specifically, how such conflicts are configured in the Salitre River basin, located in the northern part of the state of Bahia, historically characterized by the scarcity of water. The methodology used consisted of a bibliographical analysis, a discussion of secondary data and a direct research with social subjects and representatives of organizations operating in said region. The main conclusion of the study is that, in Brazil, the conflicts around water are usually characterized from a supposedly technical perspective, by the relation between water demand and supply, as well as its regulation, of an explicitly political character, that is to say, which refers to forms of appropriation and power relations that privilege the interests of the big users, the Salitre basin being regarded as typical.

Keywords: Waters. Conflict. Socioenvironmental Regulation. Salitre.

\section{CONFLIT ET REGULATION DES EAUX AU BRESIL - L'EXPERIENCE DE LA RIVIERE SALITRE}

\author{
Renata Alvarez Rossi \\ Elisabete Santos
}

Dans cet article, nous présentons la dimension politique des conflits environnementaux liés à l'eau au Brésil, dans le contexte actuel de la Loi sur les Eaux (Loi Fédérale $N^{\circ} 9.433$ / 97), en considérant tout spécifiquement la manière dont ces conflits sont configurés dans le bassin de la rivière Salitre, situé dans le nord de l'État de Bahia, historiquement caractérisé par la pénurie. La méthodologie utilisée consiste en une analyse bibliographique, une discussion des données secondaires et une recherche directe auprès des sujets sociaux et des représentants d'organisations qui travaillent dans cette région. La conclusion principale est qu'au Brésil les conflits concernant l'eau sont en général caractérisés dans une perspective prétendument technique, en fonction de la relation entre l'offre et la demande en eau et sa réglementation, explicitement à caractère politique, c'est-à-dire qui se réfère à des formes d'appropriation et à des relations de pouvoir qui privilégient les intérêts des grands utilisateurs. Le bassin de la rivière Salitre est considéré comme un exemple typique.

Mots-clés: Eaux. Conflit. Socio-environnemental. Règlement. Rivière Salitre. 